\title{
Editorial: Promiscuity and the curse of legislation
}

If ever Newspeak has been given life outside fiction, it is in the new UK pensions reform legislation. Two very large pieces of law, the Pensions Act 2004 and the Finance Act 2004, are combining inadvertently (unless there is some Machiavellian plot deep within the Treasury) to destroy what is left of UK workplace pension schemes. Such schemes have, with some minor failures, been hugely successful in providing second-tier pensions security for tens of millions of UK subjects for over 70 years, and could have coped with the challenges of longevity, fluctuating market levels and management (which they have faced over all those years). What they are incapable of surviving is counter-productive legislation. And this legislation is a warning to other jurisdictions around the world about how not to provide supplementary pension systems.

The reason for the reference to Newspeak is the constant refrain of 'simplification'. It was known and appreciated by a series of government reports that one of the burdens that UK pension schemes carried with them was the complexity and extent of the regulatory framework. The Pickering Report on 2002 legislation made it clear that, if the government wished to see such schemes continue (and it said it did, especially as the cost of the state pension scheme seemed insupportable over the longer term), it should make the system work more easily (see Table 1).

To see how far we have drifted from those admirable aspirations, all we need to do is examine two small pieces of the colossal jigsaw puzzle that is the new statutory codes. First is the reform to the ability to change the rules of schemes. In the UK, most supplementary pension arrangements are established under trust - that is a segregated pot which survived even if the sponsoring employer failed. It was thus that the funds set aside would survive to pay the pensions even if the sponsor collapsed. There are rules governing these funds and, for around a century, those rules could be changed where necessary, subject to some basic principles so that the acquired rights of scheme members were protected. Such protection was not absolute: if the trustees - those charged with the protection of the fund - thought it sensible and for the greatest good, the benefits could be amended and, in extremis, even reduced - but only if it were sensible to do so. There were few, if any, reported cases where this power was abused or left uncontrolled by the courts or where individuals had suffered grievously as a consequence.

Nonetheless, once a report into the legislative framework of pensions in the UK had been commissioned, following the Maxwell Affair in the early 1990s, it was recommended that such a position should not be left to the common law, but should be encapsulated in statute. A principle of around 50 words was then expressed in about 300 words in the Pensions Act 1995 s. 67.

It took a year or two for the practitioners of pensions to understand that there were deep flaws in the drafting 
Table 1: Pickering principles of legislative drafting

(i) Each statutory requirement (whether set out in primary or secondary legislation) should include a statement of that legislation's underlying policy aim.

(ii) Statutory requirements should focus on the objective to be achieved rather than the process needed to achieve it.

(iii) Statutory requirements should be proportionate to the stated policy aim and should avoid unnecessary complexity.

(iv) Each new piece of pensions legislation should not be considered in isolation, but should have regard to the existing law applicable to pension arrangements.

of the statute. What had been managed perfectly well for several generations was now constrained beyond breaking point by legislation, and the system became unworkable. Pensions are a dynamic and organic construct - they cannot be frozen for decades, since they need to respond to commercial and social changes. But the legislation made it all but impossible to do so.

Once this was realised, there came pressure for reform - and simplification. The pension lawyers, in particular, argued for the power to reduce benefits in certain cases (provided it was reasonable to do so). Without that power, schemes would ossify, and employers become reluctant to establish them in the first place. And the costs of complying with what was impracticable were excessive.

Now, O king, establish the decree, and sign the writing, that it be not changed, according to the law of the Medes and Persians, which altereth not. (Nunc, rex, statue edictum, et obsigna scripturam, quae non ad mutandum, secundum legem Medorum et Persarum, quae non transit.)

Daniel 6:8

But even the Medes and Persians understood that not changing a law or a rule was impractical — what they sought was a restriction on the promiscuous changing of law. And who can say that we have not been promiscuous in our law on pensions? Since 1995, just ten years ago, we have had the Pensions Act
1995, the Welfare Reform and Pensions Act 1999, the Child Support etc Act 2000 and now the Pensions Act 2004, not to mention around another 20 acts of parliament, which have a smaller or greater impact on pensions, around half a dozen European directives, several hundred law cases and hundreds of statutory instruments. We have an acute case of legal diarrhoea. The new law on protecting members from changes in pension scheme rules is not shorter, of course, it is longer. Not only is it longer, it is ten times longer. And its content means that pension schemes are frozen in eternity. More means a lot less. And simplification means complication.

If it were just an aberration from a Department of State that is out of legislative control, it might be understandable if not acceptable, but similar monstrosities have emerged from the UK Treasury. The tax structures of pensions in the UK were a miasma: around 14 different systems, none of them compatible. So the Finance Act 2004 simplified the system into one, which is a triumph - except that the drafting of the legislation is impenetrable. Set out in the Appendix is a list of the formulae which have been used to manage the funds that can be placed into schemes - and it is important to note that the terms vary according to their context, so that not all terms mean the same throughout the legislation.

It is, of course, nonsense. The question for all of us involved in the operation and 
design of pension systems is whether there is a better way. Such an aspiration may be beyond achievement, but there may be a less worse way. One way might be to relate the making of a law to success. At present, unlike actuaries, lawyers (and following the Pensions Act 2004, pension fund trustees) need no qualification to act as legislators; they have no training, they pass no exams, they have no peer review and, most of all, they are not responsible for things that go wrong. With corporate governance now the order of the day in investment matters, it is critical that the reward matches the effort, yet this is hard to discern in legislation. One of the problems is that the legislation is collective; changes and amendments rarely have names attached. Once each piece of law had its author attached to it, with a penalty or sanction affixed for judgment in, say, ten years (and also financial rewards for success), we might see significant improvements in legislation. And if we had requirements for testing and reporting of legislators, we would not see excrescences like the Finance Act 2004. Until then, employers and others who wish to establish pension arrangements for their staff will look elsewhere; and now that the European Union has an additional ten jurisdictions to choose from, they have plenty of places to look. It is unlikely that the UK will be on the shopping list of many multinationals.

Robin Ellison

Editor

Appendix: Simplified tax regime - Formulae, Finance Act 2004

$$
\begin{aligned}
& \frac{S C P}{A A} \times 100(\text { s. } 148) \\
& A P B<\frac{A A R A}{2}(\text { s. } 174)
\end{aligned}
$$

$$
\begin{aligned}
& A P B-A B-\frac{A A R A}{2}(\text { s. 174) } \\
& (A P B+P B)<\frac{V A}{2}(\text { s. 175) } \\
& R V F \times \operatorname{ARP}(\text { s. } 172) \\
& A P B<\frac{V A}{2}(\text { s. } 172) \\
& A P B+A B-\frac{V A}{2}(\text { s. } 172) \\
& (A P B+P B)<\frac{A A R A}{2}(\text { s. 173) }
\end{aligned}
$$

$\frac{D C C P}{D P C P}($ s. 186)

$\frac{U P}{D R P}($ s. 187)

$\frac{U M P}{V R} \times 100$ (s. 199)

$(R V F \times A R P)-L S$ (s. 201)

$R V F \times A R P$ (s. 200)

$\frac{U E P}{A A} \times 100$ (s. 202)

CSLA/PSLA (s. 208)

$A P C / S L A$ (s. 209)

$S L A+(S L A \times L A E F)$ (s. 207)

$\frac{C V-O V}{S L A}($ s. 211)

ROIC/SLA (s. 211)

$\frac{(R V F \times P E)-L S E-(R V F \times P B)+L S B}{S L A}$

(s. 212)

$\frac{A A T-R R A}{S L A}$ (s. 213)

$C V-O V$ (s. 214)

$(R V F \times P E)+L S E-(R V F \times P B)+L S B$

(s. 215)

$(10 \times P E)-L S E$ (s. 222)

$(10 \times P B)+L S B$ (s. 222)

$A A P \times U T$ (s. 260) $\begin{array}{cc}C S L A-A A C & \text { (Sched. 29, part 1, } \\ \text { para. 6) } & \end{array}$

CSLA/PSLA (Sched. 29, part 1, para. 7) $\frac{L S-A C}{4}$ (Sched. 29, part 1, para. 6) 
RPC $-M A R$ (Sched. 29, para. 6)

$R P C-M A R-A L S$ (Sched. 29, para. 6)

SLAN/FSLA (Sched. 29, para. 8)

SLAN/PSLA (Sched. 29, para. 8)

$A C-A P-T P L S$ (Sched. 29, para. 14)

$A C-A P-T P L S$ (Sched. 29, para. 16)

$\frac{L+T I P}{T L Y} \times N L Y($ Sched. 30, para. 4)

$A A E-A B E$ (Sched. 30, para. 7)

$A A A>A B A$ (Sched. 30, para. 9)

$A A A-A B A$ (Sched. 30, para. 9)

$\frac{\left(\frac{A L \times 100}{V A}\right)-100}{100} \times V A($ Sched. 30, para. 12)

$A O-V A$ (Sched. 30, para. 13)

$\frac{100-\left(\frac{I R \times 100}{\mathrm{PIR}}\right)}{100} \times A O($ Sched. 30, para. 14)

$\frac{\left(\frac{D L R P \times 100}{D F Y}\right)}{100}-100 \times A O$

(Sched. 30, para. 15)

$R A-A P$ (Sched. 30, para. 16)

$A \times \frac{B}{C}$ (Sched. 33, para. 10)

$\frac{R R-S L A}{S L A}$ (Sched. 34 ara 7)

$(20 \times 2 / 3 \times A R E)-(U P R E)+C P R E$

(Sched. 34, para. 9)
$25 \times A R P$ (Sched. 34, para. 10)

ETY/3 (Sched. 34, para. 16)

IAPC/SLA Sched. 34, para. 17)

$Y \times 2.5$ (Sched. 34, para. 18)

$\frac{V C P R}{4}+\operatorname{VUSLR}$ (Sched. 34, para. 24)

VULSR - APCLS (Sched. 34, para. 26)

CSLA/FSLA (Sched. 34, para. 26)

CSLA/PSLA (Sched. 34, para. 26)

$\frac{V U S L R}{V U R} \times(L S+A D)$

(Sched. 34, para. 27)

$\frac{V U S L R}{V U R} \times(L S+A P P)$

(Sched. 34, para. 27)

$\frac{V U S L R}{V U R} \times(L S+A C)$

(Sched. 34, para. 27)

$\frac{V U S L R}{V U R} \times 100($ Sched. 34, para. 29)

$\operatorname{VUSLR} \times \frac{\text { CSLA }}{F S L A}($ Sched. 34, para. 31)

$\left(V U S L R \times \frac{C S L A}{F S L A}\right)+A S L A$

$\frac{L S+A C-\left(V U R \times \frac{C S L A}{F S L A}\right)}{4}$

(Sched. 34, para. 31)

$\frac{A C V}{V} \times 100($ Sched. 34, para. 54) 